\title{
Experiment and Numerical Studies on Heat Loss in a Hydro-Distillation with Various Insulations
}

\author{
Mohd Haslizam Abdullah", ${ }^{1, *}$, Saiful Anwar Che Ghani ${ }^{2}$, and Siti Rohaida Mohamed $^{1}$ \\ ${ }^{1}$ Faculty of Mechanical Engineering, Universiti Malaysia Pahang, 26600 Pekan, Pahang, Malaysia
}

\begin{abstract}
In Asia, Agarwood oil is obtained by conventional extraction methods which consume significant energy, amount of solvents, and process time. One of the conventional extraction methods is traditional hydrodistillation using stainless steel distiller covered by concrete. This study evaluates the heat loss during agarwood during agarwood hydro-distillation process with the aim at optimizing it using insulation techniques. Six insulation materials namely, Polyurethane, Aluminum Silicate, Glass Wool, Mineral Wool and Nitrile Rubber have been investigated experimentally and numerically using software Engineering Equation Solver (EES) to determine their effectiveness in reducing the heat loss from the boiler. Interestingly, higher heat loss recorded by the boiler surrounded by the concrete than when the boiler was heated barely. The best insulations with more than $18 \%$ efficiency of bare distiller demonstrated by glass wool and polyurethane whilst the worst efficiency was Aluminum Silicate. This finding is significant to help designers to choose the insulation material for improving engineering economics of hydro-distillation process.
\end{abstract}

\section{Introduction}

Currently, there are a few methods of extracting essential oils from its plant raw material. The extraction method can be categorized as conventional method (traditional) and innovative technique (modern) [1]. The conventional extraction methods are such as by hydro-distillation [2], steam-distillation [3], solvent extraction [4], enfleurage, cohobation and maceration. The innovative extraction technique includes supercritical fluid extraction [5], microwave-assisted hydro-distillation [6] and ultrasound-assisted extraction [7]. Hydrodistillation is the oldest and most common method of extracting essential oil since it is economically viable and safe. During hydro-distillation, the essential oil components form an azeotropes mixture with water. The extraction period influences not only the yield but also the extract composition. Hydro-distillation can be attained by one of the three methods which are water distillation, water and steam distillation or direct steam distillation [8].

Hydro-distillation considered as an established method used to extract essential oils, but the process parameters are rather pragmatic than fully understood [9]. The boiler is the heat source where major of the heat is transferred from the burner. Heat loss is due to convection, conduction or radiation. In order to minimize the heat loss, insulation can be used. There are

\footnotetext{
* Corresponding author: ahaslizam@gmail.com
} 
much available insulation such as glass wool, mineral wool, nitrile rubber, and polyurethane. The insulation can minimize the heat loss through conduction because insulation has a lower value of thermal conductivity [10].

The work aims to evaluate of heat loss in hydro-distillation process by different insulation techniques towards this process of extracting agarwood by experiment and numerical studies. The result from mathematical modelling is being compared with the theoretical result and then validated with experimental results. As reducing the heat loss can improve the heat flow in the system, and then the efficiency of the boiler can be increased. Hence, the process productivity will also increase. At the same time, it also can save costs because of less power is used in the system.

\section{Methodology}

The heat transfer rate per unit area by conduction is proportional to the normal temperature gradient.

$$
\dot{q}=-k A \frac{\Delta T}{\Delta x}
$$

Where $\dot{q}$ will be the heat transfer rate and $\frac{\Delta T}{\Delta x}$ is the temperature gradient in the direction of heat flow, hot body to cold body. The positive constant, $k$ is a thermal conductivity coefficient, and the negative sign is used to satisfy the second law of thermodynamic which states that it is impossible for the energy to transfer from cold to hot. Hence the temperature gradient and direction of heat transfer are opposite to each other because temperature gradient describes that the temperature goes from lower to high temperature which opposite with the second law of thermodynamics. The equation (1) is called Fourier's law of heat conduction.

The values of heat transfer were primarily determined from the theoretical analysis which then compared to the numerical simulation values. Fig. 1 shows the schematic diagram of the boiler with insulation used in the theoretical calculation.

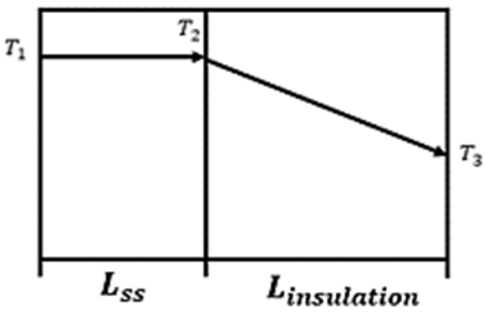

Fig. 1. Schematic diagram for the boiler with insulation

The theoretical heat loss is calculated by equation (2). Whereby, thermal resistance is through equation (3).

$$
\begin{array}{r}
\dot{Q}_{\text {loss }}=\frac{1}{R}\left(T_{1}-T_{3}\right) \\
R=\frac{L_{S S}}{k A_{1}}+\frac{L_{i n s}}{k A_{2}}
\end{array}
$$

Where $\dot{Q}_{\text {loss }}$ is the heat transfer by conduction, $k$ is the thermal conductivity, $T_{1}$ is the inside surface temperature and $T_{2}$ is the outside surface temperature. $A_{1}$ is the area of the boiler and $A_{2}$ is the total area of the boiler with insulation. $L_{s s}$ is the thickness of the boiler and $L_{i n s}$ is the thickness of the insulation. 
In this study, five types of insulation materials were used to optimize the heat loss at the boiler during the hydro-distillation process as listed in Table 1. To choose the insulation material, low thermal conductivity factor and its availability are needed to be considered.

Table 1. Insulation material selection specification.

\begin{tabular}{|c|c|c|c|c|}
\hline No & Material & $\begin{array}{c}\text { Thermal } \\
\text { conductivity }\end{array}$ & Description & $\begin{array}{c}\text { Operating } \\
\text { temperature }\end{array}$ \\
\hline $\mathbf{1}$ & Polyurethane & $0.038(\mathrm{~W} / \mathrm{mK})$ & $1000 \times 1000 \times 20 \mathrm{~mm}$ & $<150{ }^{\circ} \mathrm{C}$ \\
\hline $\mathbf{2}$ & Aluminum silicate & $0.085(\mathrm{~W} / \mathrm{mK})$ & $1000 \times 610 \times 20 \mathrm{~mm}$ & $<900^{\circ} \mathrm{C}$ \\
\hline $\mathbf{3}$ & Glass wool & $0.039(\mathrm{~W} / \mathrm{mK})$ & $1000 \times 1200 \times 20 \mathrm{~mm}$ & $<540^{\circ} \mathrm{C}$ \\
\hline $\mathbf{4}$ & Mineral wool & $0.041(\mathrm{~W} / \mathrm{mK})$ & $1200 \times 610 \times 50 \mathrm{~mm}$ & $<740^{\circ} \mathrm{C}$ \\
\hline $\mathbf{5}$ & Nitrile rubber & $0.40(\mathrm{~W} / \mathrm{mK})$ & $1000 \times 1000 \times 10 \mathrm{~mm}$ & $<150^{\circ} \mathrm{C}$ \\
\hline
\end{tabular}

The actual data from the small scale stainless steel boiler (diameter, $D=0.22 \mathrm{~m}$, height, $h$ $=0.13 \mathrm{~m}$ ) using thermocouple data acquisition module was used to get input for boundary conditions. The data was collected at water's temperature, inside surface of the boiler temperature, outside surface of the boiler temperature and ambience temperature. An electric stove rated at $810 \mathrm{~W}$ was used as a heat source to the boiler. The boiler then filled with $2 \mathrm{~L}$ of pure water and heated until the water temperature reach $100^{\circ} \mathrm{C}$. The procedure was repeated with different insulation namely glass wool, mineral wool, nitrile rubber, polyurethane, and aluminum silicate.

The software used to perform this simulation in this project is the Engineering Equation Solver (EES) [11]. The first law of Thermodynamics stated that the internal energy of a system has to be equal on the system in this work, plus or minus the heat that flows in or out of the system and any other work that is done on the system. The conservation of energy can be translated to that the total energy that enter to the system is equal to the internal energy and the heat losses from the system. The conversation energy of boiler, $\dot{Q}_{b}$ can be calculated as,

$$
\dot{Q}_{b}=\dot{Q}_{\text {internal }}+\dot{Q}_{\text {loss }}
$$

Whereby the efficiency of the system is,

$$
n=\frac{\dot{Q}_{\text {internal }}}{\dot{Q}_{b}}
$$

Where, $\dot{Q}_{b}$ is the energy from the burner, $\dot{Q}_{\text {internal }}$ is the internal energy in the system and $\dot{Q}_{\text {loss }}$ is the energy loss from the system. $n$ is the efficiency of the boiler. The transient heat transfer is used in this study because the heat transfer or the temperature change with time as the system is heated up by a burner. Therefore, a transient mathematical simulation is set up.

$$
\begin{array}{r}
\frac{\delta \dot{Q}}{\delta t}=\dot{Q}_{b}-\dot{Q}_{\text {loss }} \\
\frac{\delta T}{\delta t} \cdot m \cdot C p=\dot{Q}_{b}-U \cdot A\left(T_{i}-T_{a m b}\right)
\end{array}
$$

The first order of Euler approximation differential equation method is used to approximate with a given step size and initial values.

$$
\frac{T_{i}-T_{i-1}}{\Delta t} \cdot m \cdot C p=\dot{Q}_{b}-U \cdot A\left(T_{i}-T_{a m b}\right)
$$


Where, $m$ is the mass of the fluid, $C p$ is the heat capacity of the fluid and $U$ is the overall heat transfer coefficient. $A$ is the total area of the system, $T_{i}$ is the temperature of the fluid, $T_{a m b}$ is the temperature of the ambience and $t$ is the time. In this study, the heat is transferred in three modes which are by convection, conduction and radiation. The total heat loss can be calculated as,

$$
\begin{array}{r}
\dot{Q}_{\text {loss }}=U \cdot A\left(T_{i}-T_{\text {amb }}\right) \\
U \cdot A=\frac{1}{R_{\text {total }}}
\end{array}
$$

The total thermal resistance can be calculated as,

$$
\begin{aligned}
& R_{\text {total }}=R_{c v 1}+R_{\text {cond }}+\frac{\left(R_{c v 2} \cdot R_{r a d}\right)}{\left(R_{c v 2}+R_{r a d}\right)} \\
& R_{T}=\frac{1}{h_{i} \cdot A_{i}}+\frac{\ln \left(\frac{r_{2}}{r_{1}}\right)}{2 \cdot \pi \cdot L \cdot K_{i n s}}+\frac{1}{h_{0} \cdot A_{o}}+\frac{1}{h_{r} \cdot A_{T}}
\end{aligned}
$$

The convection heat transfer coefficient can be calculated with,

$$
\begin{array}{r}
\frac{h_{i, o} \cdot D}{k}=N u \\
h_{i, o}=N u \cdot k
\end{array}
$$

Whereby the radiation heat transfer coefficient is,

$$
h_{r}=\varepsilon \cdot \sigma \cdot\left(\left(T_{s}+273\right)^{2}+\left(T_{a m b}+273\right)^{2}\right) \cdot\left(\left(T_{s}+273\right)+\left(T_{a m b}+273\right)\right)
$$

Where in equation (9) and (10), $U$ is the overall heat transfer coefficient, $A$ is the area of the insulation, $T_{i}$ is the temperature of the fluid and $T_{a m b}$ is the temperature of the ambient. Equation (11), $R_{c v}$ is the thermal resistance of convection, $R_{c o n d}$ is the thermal resistance of conduction, $R_{\text {rad }}$ is the thermal resistance of radiation. Where in equation (12), (13) and (14), $h_{i}$ is the internal heat transfer convection of the boiler, while $h_{0}$ is the outer heat transfer convection of the boiler and $h_{r}$ is the heat transfer coefficient of radiation. $k$ is the thermal conductivity, $A_{i}$ is the internal surface area of the system, $A_{o}$ is the external surface area of the boiler, while $A_{T}$ is the surface area of the boiler with insulation. $N u$ is the nusselt number, $\mathrm{h}$ is the height of the boiler, $\mathrm{D}$ is the diameter of the system and $\varepsilon$ is the emissivity of the material and $\sigma$ is the Boltzmann's constant, $5.76 \times 10^{-8}$.

\section{Results and discussion}

Fig. 2 (A) shows the temperature over time graph of a boiler without insulation and with five different insulations. From the graph, there is no significant difference between the insulation and without the insulation on the boiler. The time is taken to reach the boiling temperature for all six only differ in a minimal margin of seconds. Without insulation, the water needed $785.9 \mathrm{~s}$ to reach boiling temperature. Mineral wool, glass wool, and polyurethane insulation needed $758.8 \mathrm{~s}, 758.4 \mathrm{~s}$ and $758.4 \mathrm{~s}$ respectively. In other hand, aluminum silicate and nitrile rubber insulation needed $767 \mathrm{~s}$ and $763 \mathrm{~s}$, respectively. This is because of the boiler is small and the mass of the water is only $2 \mathrm{~L}$. Thus, the water does not need much time to reach the boiling temperature.

Fig. 2 (B) shows the heat loss of the boiler during boiling without insulation and with five insulations. Without any insulation, the boiler has more heat loss because there is no conductive resistance. The heat loss is $48 \mathrm{~W}$ at $100^{\circ} \mathrm{C}$. The graph shows that by insulating the boiler, the heat loss can be reduced. This is because the insulation gives the boiler a thermal resistance of conduction whereby it will increase the total thermal resistance of the system. The thermal resistance, $R$ is inversely proportional to the heat loss, $\dot{Q}_{\text {loss }}$. The higher 
the thermal resistance of the boiler, the lower the heat loss of the boiler. Nitrile rubber and aluminum silicate have heat loss at $16.4 \mathrm{~W}$ and $19.75 \mathrm{~W}$ at $100^{\circ} \mathrm{C}$. The heat loss also not differs significantly as the boiler capacity is only 2 liters of water.
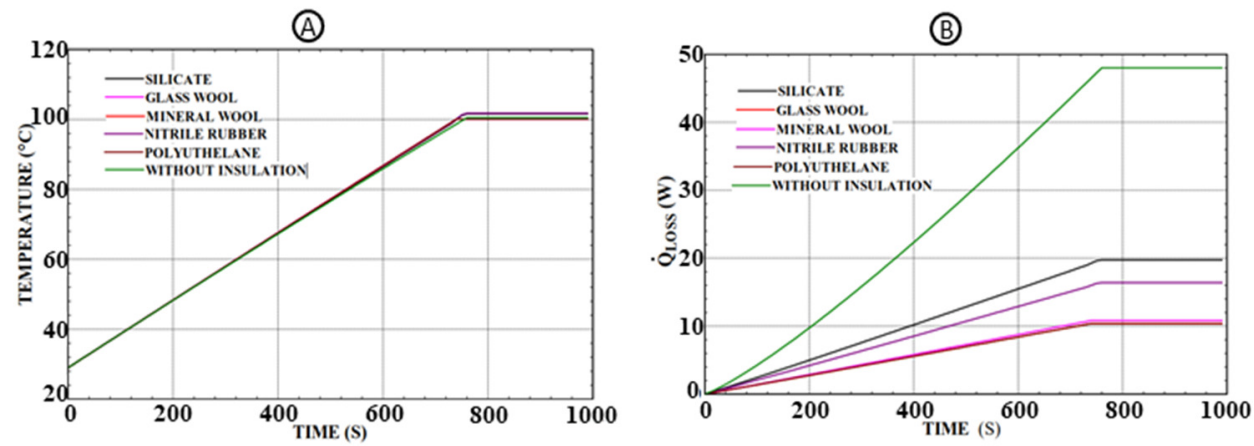

Fig. 2. (A) Water's temperature against time during boiling graph. (B) Heat loss against time during boiling graph

Table 2 shows the comparison between theoretical and numerical results of heat loss. From the calculation, it shows that the values of theoretical are almost similar to the numerical result. In the numerical calculation, the small discrepancies of heat loss are due to consideration of natural convection and radiations. It can be concluded that the numerical result is reliable enough to do further investigation and validation with the experimental results.

Table 2. Comparison from theoretical and numerical result.

\begin{tabular}{|c|c|c|}
\hline \multirow{2}{*}{ Insulation } & Heat loss of the boiler at boiling temperature (W) \\
\cline { 2 - 3 } & Theoretical & Numerical \\
\hline Glass wool & 10.41 & 10.40 \\
\hline Polyurethane & 10.36 & 10.38 \\
\hline Mineral wool & 10.82 & 10.84 \\
\hline Nitrile rubber & 15.87 & 16.40 \\
\hline Aluminum silicate & 19.61 & 19.71 \\
\hline
\end{tabular}

The results of the time taken to boil the water with different insulations from simulation and experiments are shown in Table 3. The percentage errors show a high correlation between the numerical model and experiment.

The targeted industrial scale hydro-distillation setup is using stainless steel boiler (diameter, $D=1 \mathrm{~m}$, height, $h=0.65 \mathrm{~m}$ ) with $330 \mathrm{~kg}$ water mass and $4400 \mathrm{~W}$ of heat supply capacity. As depicted in Fig. 3, it is interesting to know that the current boiler with concrete cover has higher heat loss than the boiler without any insulation. The heat loss is $1155 \mathrm{~W}$ at boiling temperature and efficiency of $73.75 \%$. The time taken for the water to reach the boiling temperature is 7 hours and 52 minutes. This is because of the low thermal resistance of conduction, which is 0.01728 . The concrete have $1.977 \mathrm{~W} / \mathrm{m} . \mathrm{K}$ thermal conductivity. Therefore, the concrete acts as a conductor instead of an insulator but it is a poor conductor due to the low thermal conductivity when compared with the stainless steel. While without insulation, the system will have a heat loss which is $838.1 \mathrm{~W}$ at boiling temperature, which can lead the boiler to have $80 \%$ efficiency. The time taken for the water to reach the boiling temperature is 7 hours and 30 minutes. 
Table 3. Experimental and numerical data comparison.

\begin{tabular}{|c|c|c|c|}
\hline \multirow{2}{*}{ Insulation } & \multicolumn{3}{|c|}{ Time Taken for the water to reach boiling temperature (s) } \\
\cline { 2 - 4 } & Experimental & Numerical & Percentage Error (\%) \\
\hline No insulation & 810.2 & 780.0 & 3.80 \\
\hline Glass wool & 738.0 & 730.0 & 1.09 \\
\hline Polyurethane & 704.6 & 697.0 & 1.09 \\
\hline Mineral wool & 710.0 & 723.8 & 1.90 \\
\hline Nitrile rubber & 710.0 & 709.4 & 0.08 \\
\hline Aluminum silicate & 799.0 & 780.0 & 2.4 \\
\hline
\end{tabular}

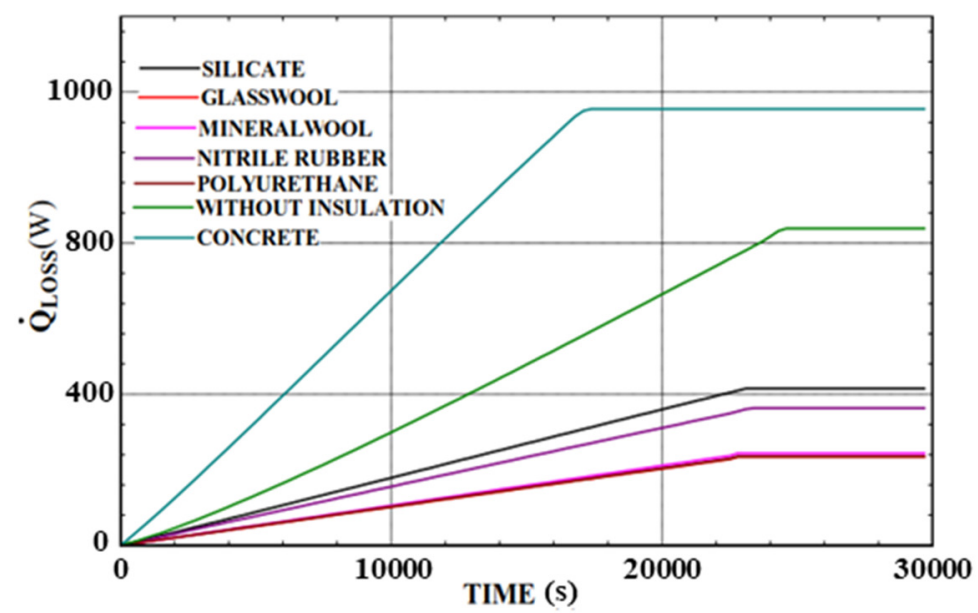

Fig. 3. Heat loss versus time graph for different insulation materials

A boiler which insulated with glass wool has the lowest heat loss which is $233.7 \mathrm{~W}$ at boiling temperature. The time taken to reach the boiling temperature for glass wool, mineral wool and polyurethane is reduced as low as 6 hours 29 minutes. Furthermore, the highest efficiency of the boiler reaches to $94.7 \%$ for glass wool, $94.5 \%$ for polyurethane and $94.3 \%$ for mineral wool. The results from the simulation is summarizes in Table 4.

Table 4. Simulation result for industrial scale hydro-distillation system.

\begin{tabular}{|c|c|c|c|}
\hline Insulation & $\dot{\boldsymbol{Q}}_{\text {loss }}(\mathbf{W})$ & Efficiency (\%) & Time to boil \\
\hline Concrete & 1155.0 & 73.8 & $8 \mathrm{hr} 30 \mathrm{~m}$ \\
\hline No insulation & 838.1 & 80.0 & $7 \mathrm{hr} 30 \mathrm{~m}$ \\
\hline Glass wool & 233.7 & 94.7 & $6 \mathrm{hr} 29 \mathrm{~m}$ \\
\hline Mineral wool & 243.2 & 94.3 & $6 \mathrm{hr} 30 \mathrm{~m}$ \\
\hline Nitrile rubber & 362.8 & 91.7 & $6 \mathrm{hr} 42 \mathrm{~m}$ \\
\hline Polyurethane & 235.3 & 94.5 & $6 \mathrm{hr} 29 \mathrm{~m}$ \\
\hline Aluminum silicate & 414.7 & 90.5 & $6 \mathrm{hr} 47 \mathrm{~m}$ \\
\hline
\end{tabular}




\section{Conclusions}

The experiment showed that the results obtained only have $0.08 \%$ to $3.8 \%$ error after being validated with the numerical simulation result, which may occur because of the random error and instrument error. Therefore, the numerical simulation can be used to analyze the boiler system used in industrial application. The current boiler used at the industry has concrete as insulation. This work revealed the concrete not acted as an insulator but rather as conductor because it increased the heat loss without insulation from $838.1 \mathrm{~W}$ to $1155 \mathrm{~W}$. In fact, the industry increased the heat loss by $317 \mathrm{~W}$. The numerical simulation result showed that the glass wool has the best performance from others insulation materials. By using glass wool insulation at the boiler, it can reduce the boiling time from 8 hours and 30 minutes to 6 hours 29 minutes. It also can minimize the heat loss with only $233.7 \mathrm{~W}$.

The authors gratefully acknowledge the financial support by the Malaysia Ministry of Higher Education for Fundamental Research Grant (RDU160015) and Research Acculturation Collaborative Effort (RDU151313) and Universiti Malaysia Pahang (www.ump.edu.my) under grants PGRS160385 and RDU150338. The author also thanks the industrial partner from IGawa Resources Enterprise for providing insight and expertise that greatly assisted in the present research work.

\section{References}

1. M. Gavahian, A. Farahnaky, R. Farhoosh, K. Javidnia, F. Shahidi, Food Bioprod. Process 94, 50-58 (2015)

2. V. A. Jok, N. C. Radzi, and K. H. K. Hamid, Procd. Soc. Behv. 195, 2443-2450 (2015)

3. J. Pornpunyapat, P. Chetpattananondh, and C. Tongurai, Bangladesh J. Pharmac. 6, 1824 (2011)

4. J. A. Fisher, M. J. Scarlett, and A. D. Stott, Environ. Sci. Technol. 31, 1120-1127, (1997)

5. G. Sodeifian, S. A. Sajadian, and N. Saadati Ardestani, J Supercrit.Fluid 127, 146-157 (2017)

6. H. S. Kusuma and M. Mahfud, J Appl. Medic and Aromatic Plants 4, 45-54 (2017)

7. M. Boukroufa, C. Boutekedjiret, L. Petigny, N. Rakotomanomana, and F. Chemat, Ultrason Sonochem, 24, 72-79 (2015)

8. L. Peyron and H. Richard, Épices et aromates, Paris: Tec et Doc-Lavoisier (1992)

9. L. P. Stanojevic, N. S. Radulovic, T. M. Djokic, B. M. Stankovic, D. P. Ilic, M. D. Cakic Ind. Crop. Prod. 67, 509 (2015)

10. T. L. Bergman, F. P. Incropera, A. S. Lavine, and D. P. Dewitt, Introduction to heat transfer (John Wiley \& Sons, 2011)

11. S. A. Klein and F. Alvarado, EES: Engineering equation solver for the Microsoft Windows operating system (F-Chart software, 1992) 